\title{
Students and industrial sponsorship
}

Richard Pearson*

\section{In certain specialized areas the role of industry in supporting British undergraduates is significant. It can have unexpected consequences.}

STUDENT finance has been high on the debating agenda for a number of years. The value of the means-tested grant for British undergraduates is currently $£ 1,660$ per annum plus fees although few students receive the full amount because of the means test, with many parents not making their full contribution. Although the real value of the grant was fairly stable throughout the $1970 \mathrm{~s}$, it has fallen by about 10 per cent in the past couple of years (Fig. 1). Even so, the British undergraduate is considered better off than his contemporary in Japan, who has to take out a loan, while students in most of Europe and North America have to rely on a combination of loans (often at low rates of interest) and grants, supplemented in some cases by scholarships. In the United Kingdom, the current pressure to reduce public expenditure means that loan

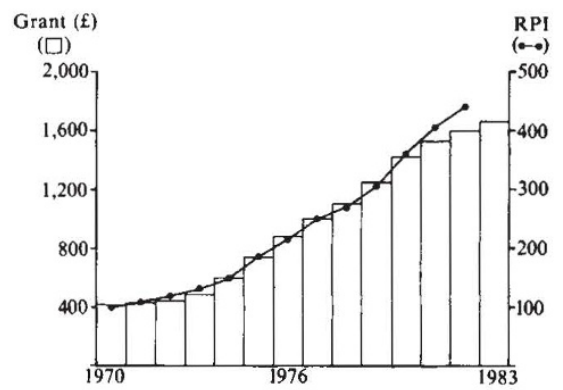

Fig.1 The "real" value of the student grant in Britain.

schemes could well be reconsidered in the next few years, although opponents argue that loans lead to only limited cost savings, while seriously affecting certain groups, such as women and those from poorer homes.

One source of finance rarely considered in this debate is industrial sponsorship. The full extent, in terms of money spent and numbers involved, is unknown. Most sponsorship is, however, concentrated in the area of engineering, with a smaller involvement in some of the pure sciences and in business and related studies. A recent report ${ }^{1}$ from the Institute of Manpower Studies has shown that more than 2,200 (one in four) final-year engineering students were sponsored in 1983, which suggests the total number of sponsored students in higher education is probably over 10,000 . Total expenditure by industry is likely to be several million

*Institute of Manpower Studies, University of Sussex, Falmer. Brighton BN1 9RF, UK. pounds each year

Sponsorship can take many forms. A student may be a salaried member of the staff of the sponsoring organization, he or she may receive a bursary worth up to $£ 915$ a year on top of the mandatory grant, or may have some mix of mandatory grant, bursary and salary when working in vacations or on periods of industrial work if on a sandwich course.

Employers sponsor students for a variety of reasons. For some it is a form of patronage, helping existing employees, often bright craftsmen and technicians, to advance their careers. For most, however, it is a means of guaranteeing a supply of well-trained recruits in the future, particularly in the "shortage" subjects of electronic and mechanical engineering. Sponsorship is also seen as providing an opportunity to make a detailed assessment of an individual's capabilities, as a means of influencing students' choice of subject and institution of study, as a way of attracting high quality school leavers, and to improve collaboration between industry and higher education. There is of course a financial cost involved, up to $£ 4,000$ per student over the duration of the course, and there is often the need to provide training and work experience.

In the past, some employers have sought legally to bind the student to the company for a period of years after graduation but this now happens only in the armed forces where the undegraduate becomes an employee. In recent years, 50-80 per cent of sponsored graduates have joined their sponsoring organizations, with each side rejecting the other in roughly similar proportions; some employers are, however, able to retain all those they want. Most students are sponsored from the start of their course, with the majority recruited directly from school, of ten only from local areas. More than half the employers limit their sponsorship students to particular universities, and in a few cases to particular polytechnics.

Among the 2,200 final-year engineering graduates sponsored in 1983 , most were to be found in mechanical ( 38 per cent) and electrical/electronic ( 35 per cent) engineering, and relatively few in civil or chemical engineering. While two-thirds were in universities, the proportions of sponsored students, when compared on a subject basis, were similar in the universities and the polytechnics. Overall, 35 per cent of mechanical and 28 per cent of electrical/ electronic engineers were sponsored (Fig.
2). It is interesting that it was the largest university/polytechnic departments (with over 50 final year students) that had the highest level of sponsorship and the middle-sized departments (25-49 final year students) that had the lowest.

In the past five years, more than 250 employers have been involved in sponsorship, some with only an occasional student, others with a regular intake of 50 to 100 a year. The number of companies sponsoring students has fallen as training budgets and recruitment levels have been cut back because of the recession. Nevertheless, the number of places on offer has grown slightly, with the number of places for electronic engineers increasing dramatically in response to expected shortages in future years.

Looking to the future, most employers expect to continue with their current sponsorship policies, while one in five expect to increase and one in seven to decrease their level of sponsorship. In the case of electronics, sponsorship has been rising rapidly. As a result, perhaps half of the graduates expecting to enter the labour

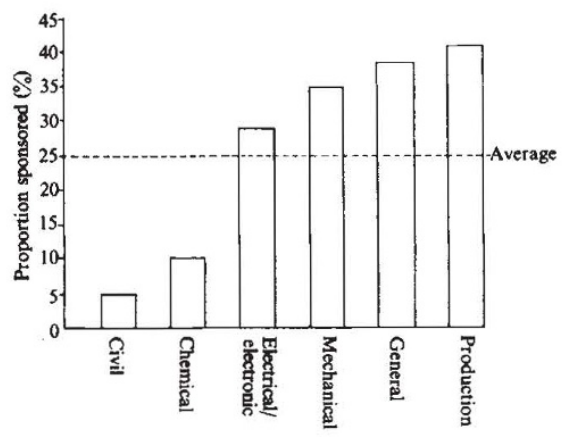

Fig.2 Proportion of final-year engineering students at UK universities and polytechnics sponsored by an employer during 1983.

market in the next few years will already be notionally committed to a particular employer. While not all will join that employer, it seems that the "free" market of electronics engineering graduates seeking employment will be even smaller than the already inadequate supply than has been forecast. This will compound the future recruitment difficulties of all types of employers, although the sustained high level of sponsorship may have an influence on subject and career choice by would-be students.

1. Gordon, A., Hutt, R. \& Pearson, R. Undergraduate Sponsorship: Implications for the Labour Market, Interim Report (IMS, 1983). 